Journal of Advanced Research in Fluid Mechanics and Thermal Sciences

Journal homepage: www.akademiabaru.com/arfmts.html ISSN: 2289-7879

\title{
Effect of Electrical Load On the Emulsification Methods of Inline Mixing System RTES Produced by The Static Mixer and Ultrasonic on Fuel Consumption and Emission Characteristics
}

\author{
Wan Nur Izzati Wan Mahdi ${ }^{1}$, Ahmad Muhsin Ithnin ${ }^{1,}{ }^{*}$, Wira Jazair Yahya ${ }^{1}$, Muhammad Adib Abdul \\ Rashid $^{1}$, Muhamad Aliff Zaharim ${ }^{1}$, Mikhael Mukhlasein Ahmad ${ }^{1}$, Hasannuddin Abd Kadir ${ }^{2}$, Ili \\ Fatimah Abdul Razak ${ }^{1}$ \\ 1 Advance Vehicle System (AVS), Malaysia-Japan International Institute of Technology, Universiti Teknologi Malaysia, Jalan Semarak, 54100 Kuala \\ Lumpur, Malaysia \\ 2 Faculty of Mechanical Engineering, Universiti Teknologi MARA (UiTM) Johor, Campus Pasir Gudang, 81750 Masai Johor, Malaysia
}

\section{ARTICLE INFO}

\section{Article history:}

Received 8 May 2020

Received in revised form 25 August 2020

Accepted 17 September 2020

Available online 23 November 2020
Keywords:

Electrical load; fuel consumption; non-

surfactant emulsion; static mixer

\section{ABSTRACT}

The Water-in-Diesel emulsion (W/D emulsion) imposed the benefit of alternative fuel by reducing the main emission problems in the diesel engines such as Particulate Matters (PM) and Nitric Oxides $\left(\mathrm{NO}_{\mathrm{x}}\right)$ emissions. However, the main issue of W/D emulsion was dependency on surfactant which creates a huge barrier to commercialize this alternative fuel. Therefore, a new concept namely as the Real-Time Non-Surfactant Non-Emulsification System (RTES) was introduced to eliminate the surfactant in W/D emulsion. However, the effect of the electrical load of RTES operation in diesel engine vehicles is still unknown, especially on fuel consumption. Hence, this paper focussed on the effect of electrical load on the emulsification methods of inline mixing system RTES produced by the static mixer and ultrasonic on fuel consumption and emission characteristics. There are two different methods of emulsification made motor and static mixer (EMS) and motor, ultrasonic and static mixer (EMUS) from the RTES were tested of the light-duty lorry under the engine speed of 2200rpm. It is found that the electrical load from the operation of RTES increased the fuel consumption by $1.0 \%$ compared to the B10 fuel but reduced by $1.5 \%$ when the EMS emulsion fuel was applied. The EMS and EMUS emulsion exhibit the same pattern of $\mathrm{NO}_{\mathrm{x}}$ reduction by $7 \%$ However, EMS and EMUS increased by $20 \%$ and $16.5 \%$ for CO emission and $16.9 \%$ and 9.7\% for $\mathrm{HC}$ emission respectively compared to B10 fuel. Overall, the electrical load in the RTES operation slightly consumed fuel consumption but the introduction of the static mixer in the RTES system had successfully be applied without deteriorated the benefit of emulsion fuel.

\section{Introduction}

\footnotetext{
* Corresponding author.

E-mail address: ahmadmuhsin@utm.my
}

https://doi.org/10.37934/arfmts.78.1.8899 
The wide range application of diesel engines in various industries such as agriculture, transportation, and power generation has made this engine still favourable until now because it is very powerful, robust and offers better fuel efficiency [1-2]. Despite these advantages, the diesel engine still gives drawback to human and environment due to emission exhausted from this engine likes Nitrogen Oxides ( $\mathrm{NO}_{\mathrm{x}}$ ) and Particulate Matters (PM). PM alone or in combination with other air pollutants can cause respiratory and cardiovascular problems, while $\mathrm{NO}_{\mathrm{x}}$ and $\mathrm{PM}$ can cause acid rain, climate changes, water and soil deterioration in environmental problems [3]. Due to these severe issues, strict regulations such as the Kyoto Protocol was introduced [4] to mitigate these problems.

A lot of research studies had been done to meet this stringent regulation. The introduction of after-treatment technologies in the diesel engine able to address the $\mathrm{NO}_{\mathrm{x}}$ and $\mathrm{PM}$ emission. For example, $\mathrm{NO}_{\mathrm{x}}$ Absorber Catalysts (NAC) and Selective Catalytic Reduction (SCR) can reduce $\mathrm{NO}_{\mathrm{x}}$ emission in significant quantities. Plus, Diesel Oxidation Catalysts (DOCs) and Diesel Particulate Filters are popular devices used for PM reductions [5]. These after-treatment devices are interesting to be applied in diesel engine application but these devices are only able to reduce only one emission problem, not entirely [6]. Furthermore, this technology required some modification in the diesel engine which is not very cost-effective. Hence, fuel emulsification gains the attention in diesel engine studies because of its potential in reducing hazardous exhaust emissions such as $\mathrm{NO}_{\mathrm{x}}, \mathrm{PM}$, smoke, and other pollutants [7-8] without retrofitting diesel engine itself.

The Water-in-Diesel emulsion or W/D emulsion is a promising alternative fuel that could contribute to the world's need and comply with the strict requirement of world emission regulations [9]. Moreover, this kind of fuel does not need the existing diesel engine to be modified and it can directly be combusted into the engine. The W/D emulsion is an emulsion formed from the combination of diesel and water with the aid of a surfactant. The term emulsion is defined as a mixture of two or more immiscible liquids and should have dispersed phase and continuous phase [10-11]. Usually, the surfactant is added in the emulsion to keep the emulsion stable for a long time. However, the stability of emulsion depends on several factors such as types of surfactants and its quantity, amount of water and its droplet size, and mixing operation such as speed, temperature, mixing duration, etc [12].

The advantage of W/D emulsion is the special occurrence happens during the combustion of W/D emulsion, which is known as the micro-explosion phenomenon, or also known as the secondary atomization. The micro-explosion phenomenon is a phenomenon where the whole W/D emulsion droplet breaks up into smaller droplets quickly, and the water embedded inside the diesel puffs and explodes into fine mists [11]. This phenomenon happens very fast where the water droplet trapped inside diesel fuel evaporates quickly (due to the difference in the boiling point of water and diesel). The presence of water in W/D emulsion improved the combustion process because of these fuel droplets fuel breaks into smaller droplets thus enhancing more evaporation in surface area of droplets which resulting better air-fuel mixing in burning fuel [13-14]. Furthermore, this phenomenon significantly reducing emission especially NOx and PM in diesel engine exhaust emission

A new concept was introduced by Ithnin et al., [15] where the W/D emulsion could be produced without surfactant. This device is called as Real-Time Non-Surfactant Emulsification System (RTES) [15] which mixes water and diesel inline without a surfactant and supplies it directly into the engine. In his study, this RTES system was tested on a single-cylinder diesel engine generator with different load conditions at an engine speed of 3000rpm. The result found that the non-surfactant emulsion (UW/D) increased the brake thermal efficiency (BTE) by $3.59 \%$ and reduced the brake specific fuel consumption (BSFC) by $3.89 \%$. Plus, UW/D emulsion significantly reduced the NOx and PM by $31.66 \%$ and $16.33 \%$ respectively, compared to the stable emulsion (SW/D) with surfactant and diesel fuel 
[15]. Another study conducted by Ramlan et al., [8] on the performance and emissions of a lightduty diesel vehicle fuelled with non-surfactant low-grade diesel emulsion compared with a highgrade diesel in Malaysia [8]. In that study, the test was executed by using a light-duty truck under transient load on a chassis dynamometer. The RTES system was installed inside the lorry and the W/D emulsion fuel made of low-grade diesel (EDE2) and water was produced inside the lorry. The result showed that emulsion from low-grade diesel (EDE2) improved fuel consumption by $7.39 \%$ compared to high-grade diesel (DE5) fuel. However, EDE2 fuel produced slightly higher NOx and CO compared to DE5. Another study conducted by Mazlan et al., [16] on the effect of water percentages in nonsurfactant emulsion fuel produced by RTES on performance and exhaust emissions of a light-duty truck [16]. The experiment set up for this research was a lorry equipped with RTES tested under West Virginia University (WVU) 5 Peak Cycle on a chassis dynamometer. The various fractions of water content were tested to identify the optimum water percentage and RTES was controlled during the testing. The results revealed that the emulsion with $6.5 \%$ of the water produced better fuel consumption compared to other water percentages. Moreover, E6.5 emulsion had the highest emission reduction on the smoke number and NOx emission compared to other fraction emulsion fuels and diesel fuel. However, those authors did not mention and consider the attached device or system as a load in their research. From the literature review [15, 17-18], this system consists of various electrical components such as water pump, solenoid valve, controller, ultrasonic driver, ultrasonic transducer and dc motor which this system might consumed a lot of electrical energy. Plus, there is no research conducted to measure the electrical load of RTES system which this system will affecting on the fuel consumption due to attached RTES system on the vehicle.

Recently, the study of static mixers intrigued many researchers because static mixers are widely used in various industry especially in mixing and preparation of a mixture [19]. The integration of the static mixer in the inline mixing system seems very promising and interesting because the static mixer is a motionless mixer with no electrical or other energy to move that part. Moreover, there is a lack of study on the emulsification of W/D emulsion by using a static mixer. Therefore, this paper was bringing the idea of how much electrical consumed in RTES system that effecting fuel consumption and application of static mixer in RTES system. Thus, this study will focus on the effect of electrical load on the emulsification methods of inline mixing system RTES produced by the static mixer and ultrasonic on fuel consumption and emission characteristics.

\section{Experiment setup and procedure}

\subsection{Fuel Preparation}

In this study, the main fuel used was standard commercialized diesel fuel in Malaysia (Petron Diesel Max) which is known as Euro $2 \mathrm{M}$ with $10 \%$ of biodiesel POME (Palm oil Methyl Ester). In this research, this diesel fuel will be classified as B10 diesel fuel. On the other hand, the emulsion fuel was made up of B10 diesel fuel and Malaysia tap water. Table 1 showed the specification of tap water while Table 2 showed the specification of Malaysia B10 diesel fuel. For emulsion fuel, each fuel has the same water content for stability test and engine testing which is $7 \%$ of water content. The emulsion was produced using the RTES device equipped with a static mixer. Table 3 showed the specification of the static mixer. 
Table 1

Characteristics of tap water [20]

\begin{tabular}{ll}
\hline Specification & Tap water \\
\hline Density, $\mathrm{g} / \mathrm{cm} 3,25{ }^{\circ} \mathrm{C}$ & 1.02412 \\
Specific conductivity, $\mathrm{HS} / \mathrm{cm}, 25^{\circ} \mathrm{C}$ & 0.0532 \\
Viscosity, milipoise, $25^{\circ} \mathrm{C}$ & 9.02 \\
Vapour pressure, $\mathrm{mm} \mathrm{Hg}, 20^{\circ} \mathrm{C}$ & 17.4 \\
Isothermal compressibility, vol/atm, $0{ }^{\circ} \mathrm{C}$ & $46.4 \mathrm{E}-6$ \\
Surface tension, dyne $/ \mathrm{cm}, 0{ }^{\circ} \mathrm{C}$ & 72.74 \\
Specific heat, $\mathrm{J} / \mathrm{g}{ }^{\circ} \mathrm{C}, 17.5^{\circ} \mathrm{C}$ & 3.898 \\
The temperature of Maximum Density, ${ }^{\circ} \mathrm{C}-3.25$ & -3.25 \\
Freezing point, ${ }^{\circ} \mathrm{C}$ & -1.91 \\
\hline
\end{tabular}

Table 2

Specification of Petron Diesel Max Malaysia [21]

\begin{tabular}{ll}
\hline Properties & Value \\
\hline Density at $15^{\circ} \mathrm{C}, \mathrm{kg} / \mathrm{l}$ & 0.8372 \\
Kinematic Viscosity at $40^{\circ} \mathrm{C}, \mathrm{cSt}$ & 3.400 \\
Flash Point, ${ }^{\circ} \mathrm{C}, \mathrm{PMCC}$ & 68 \\
Sulfur, ppm & 320 \\
Cetane Number & 62.5 \\
Distillation: ${ }^{\circ} \mathrm{C} 95 \%$ Recovery & 370.0 \\
FAME content, \% vol. & 10.0 \\
Cloud Point, ${ }^{\circ} \mathrm{C}$ & 13 \\
\hline
\end{tabular}

Table 3

Specification of the static mixer

\begin{tabular}{ll}
\hline Parameters & Value \\
\hline Model & MA5.4-17S \\
Material & Polypropylene (PP) \\
Length & $103 \mathrm{~mm}$ \\
Inner diameter size & $5.4 \mathrm{~mm}$ \\
Feature & Spiral helix structure with high degree mixing \\
\hline
\end{tabular}

\subsection{Stability Measurement}

The emulsion produced from the motor and static mixer (EMS) and the emulsion from the motor, ultrasonic and static mixer (EMUS) underwent the stability test before being tested on the engine. The purpose of this test is to study the stability of the non-surfactant emulsions made by different methods. Figure 1 showed the arrangement of stability test and Figure 2 showed the RTES system equipped with static mixer. In this testing, the Start/ Stop controller was set to produce the same amount of water in both emulsions. The diesel and water were introduced in the RTES and the mixing time for emulsion was 1 minute. After the emulsion was mixed, a sample of emulsion produced was collected by using a $50 \mathrm{ml}$ test tube with $0.1 \mathrm{ml}, 0.5 \mathrm{ml}, 1.0 \mathrm{ml}$ and $1.5 \mathrm{ml}$ of the graduation mark. As soon as the sample was collected, the time taken was recorded by using a time stopwatch while the separation video was recorded by using the digital camera. This process was repeated three times for each type of emulsion and the average value was calculated. 


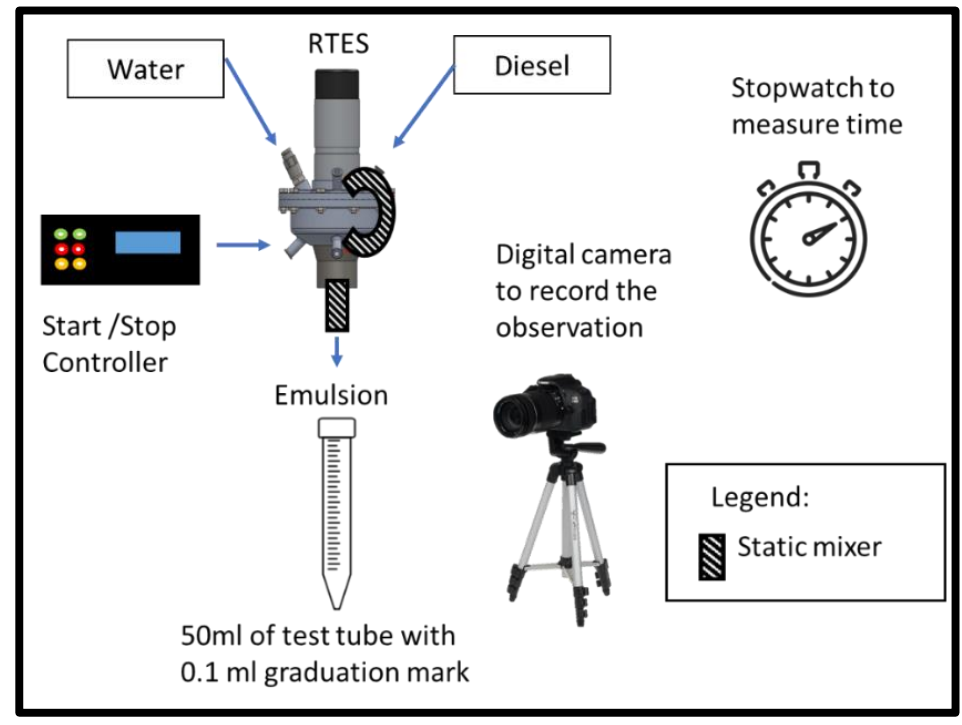

Fig. 1. Configuration of stability test set up

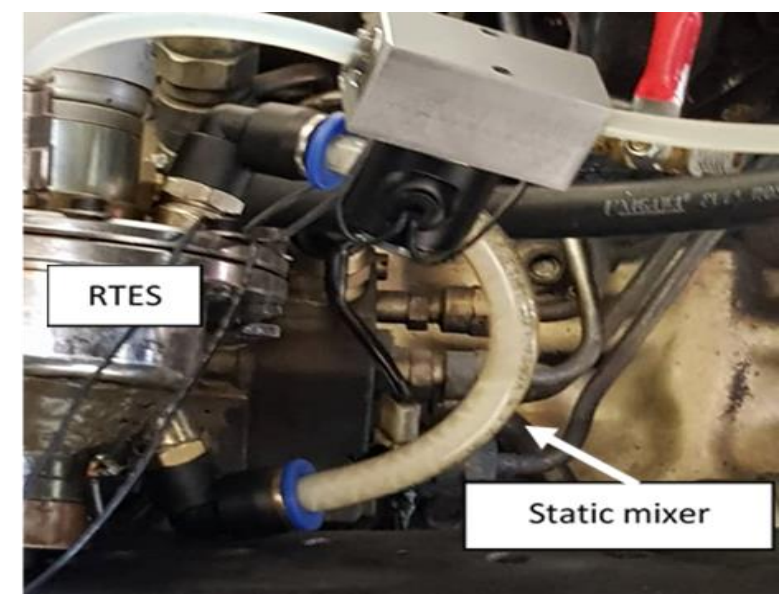

Fig. 2. RTES with static mixer

\subsection{Engine Testing Set Up}

The experimental investigation was carried out using Malaysia standard Diesel fuel and the emulsion produced from difference method EMS and EMUS with the same amount of water which about $7 \%$ water content. The test was carried out on a light-duty lorry Isuzu NHR 55E (4JB1) with parameters showed in Table 4. Some arrangement of the experiment set up was made to increase the accuracy of the experiment conducted. In this testing, the main source to operate the RTES was from the battery installed in the lorry. Figure 3 showed the experiment set up for this study. The experiment was conducted with an engine speed of 2200rpm for 5 minutes and the gas analyser was used to measure $\mathrm{NO}_{x}, \mathrm{CO}$ and $\mathrm{HC}$ emission for diesel, EMS and EMUS. The gas analyser used in this study was ECOM J2KN Pro portable gas analyser. Table 5 showed the specification of ECOM J2KN Pro portable gas analyser. Two tanks for diesel fuel were prepared to measure fuel consumption. The weight of the second diesel tank was measured by using a digital weight scale with $1 \mathrm{~g}$ accuracy. Before the testing started, the diesel fuel was supplied from the first tank. After the engine has stabilized with a constant speed of 2200rpm, the valve for the second tank was opened and the data measurements started to be recorded. The test was repeated 3 times for each type of fuel and the average measurement for all tested was recorded. 
Table 4

Test Vehicle specification

\begin{tabular}{ll}
\hline Parameter & Specification \\
\hline Model & Isuzu NHR 55E (4JB1) \\
Fuel injection system & Direct injection \\
Cylinder & 4 cylinder in-line \\
Cooling system & Water-cooled \\
Displacement $(\mathrm{L})$ & 2.8 \\
Bore $x$ stroke $(\mathrm{mm})$ & $93 \times 102$ \\
\hline
\end{tabular}

Table 5

Specification of ECOM J2KN pro portable gas analyser [22]

\begin{tabular}{llll}
\hline Measurement & Range & Accuracy & Resolution \\
\hline Oxygen & $0-21$ vol\% & \pm 0.3 vol\% & 0.1 vol\% \\
Carbon Monoxide & $0-40,000 \mathrm{ppm}$ & $\pm 2 \%$ Measured* & $5 \mathrm{ppm}$ \\
Nitric Oxide & $0-4,000 \mathrm{ppm}$ & $\pm 2 \%$ Measured* & $1 \mathrm{ppm}$ \\
Nitrogen Dioxide & $0-500 \mathrm{ppm}$ & $\pm 2 \%$ Measured* & $1 \mathrm{ppm}$ \\
Combustibles & $0-6.00 \mathrm{vol} \%$ & $\pm 2 \%$ Measured* & $0.01 \mathrm{vol} \%$ \\
Gas Temperature & $32-1800 \mathrm{~F}$ & $\pm 2 \%$ Measured* & $1 \mathrm{deg} \mathrm{F}$ \\
Ambient Temperature & $0-250 \mathrm{~F}$ & $\pm 2 \%$ Measured* & $1 \mathrm{deg} \mathrm{F}$ \\
Draft / Pressure & $\pm 40 * \mathrm{H} 2 \mathrm{O}$ & $\pm 2 \%$ Measured* & $0.1 \% \mathrm{H} 2 \mathrm{O}$ \\
O2 Correction & $0-20 \%$ Oxygen & Calculated & \\
Carbon Dioxide & $0-C O 2$ max of fuel & Calculated & \\
Efficiency (Eta) & $0-99.9 \%$ & Calculated & \\
Excess Air (Lambda) & $1-$-infinity & Calculated & \\
\hline
\end{tabular}

*Accuracy: When calibrated prior to use per ECOM America, Ltd specifications.

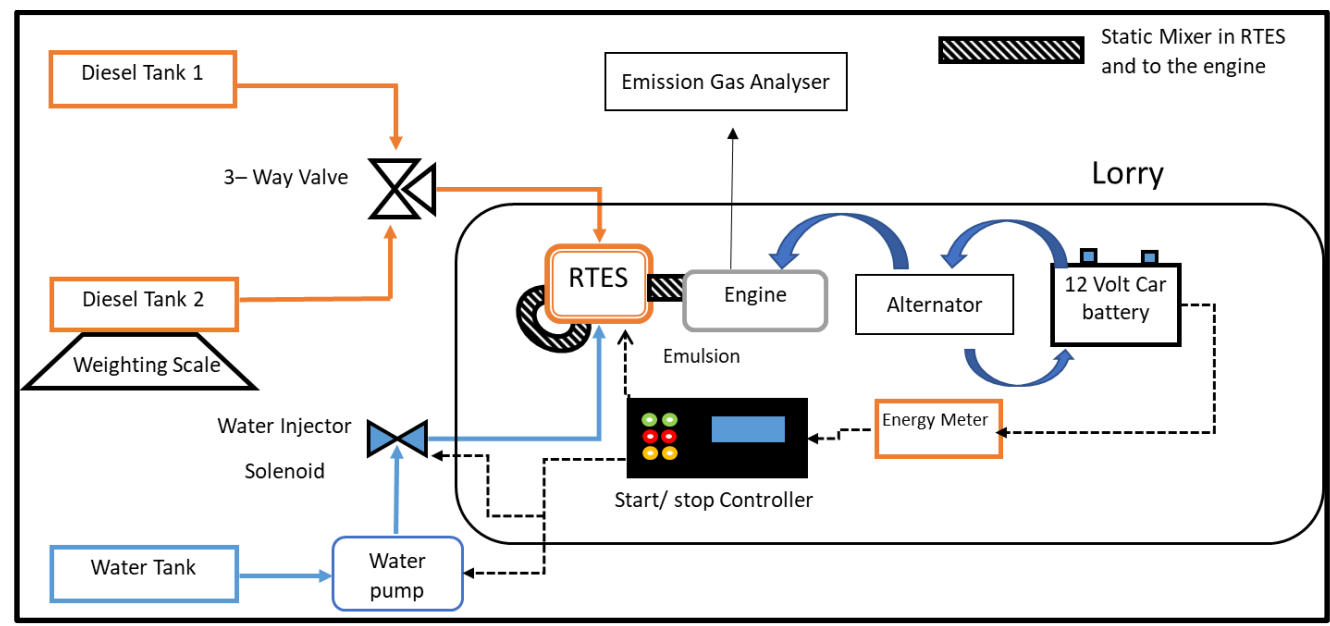

Fig. 3. Experiment set up on the test vehicle

\section{Result and Discussion}

\subsection{Emulsion Stability}

Figure 3 showed the stability of emulsion to reach $0.1 \mathrm{ml}$ water separation. It can be observed that EMUS - has the longest stability time compare to EMS. Figure 4 and Figure 5, it shows that EMUS emulsion started to destabilize after 143 seconds whereby EMS is only 52 seconds. This is because the presence of ultrasonic in emulsification of EMUS helps prolong the stability of emulsion compared to EMS.

Although both EMUS and EMS emulsion were made from the same amount of water, however, the EMUS emulsion was creamier and more whitish compared to EMS emulsion. During the 
formation of these emulsions, the water droplet size could be different because the ultrasonic supplied more energy to produce smaller water droplet sizes compared to static mixer and motor. The absence of surfactant enhancing the rate of emulsion to destabilize. From Figure 5, the translucent layer seen is the water layer that had been separated from the emulsion and sedimented at the bottom of the emulsion. The occurrence of this phenomenon was related to the coalescence process and Ostwald ripening.

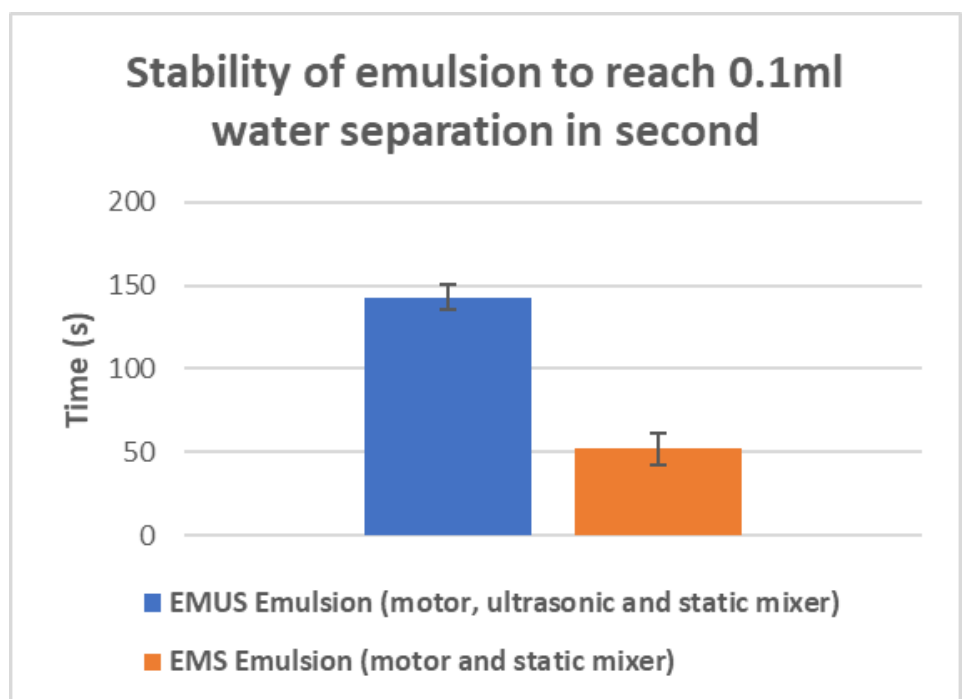

Fig. 4. Stability of emulsion to reach 0.1 water separation in seconds

\begin{tabular}{|c|c|c|c|c|}
\hline $\begin{array}{l}\text { condition/ } \\
\mathrm{ml}\end{array}$ & 0.1 & 0.5 & 1.0 & 1.5 \\
\hline \multirow{2}{*}{$\begin{array}{l}\text { Emulsion } \\
\text { produced } \\
\text { by motor, } \\
\text { ultrasonic } \\
\text { and static } \\
\text { mixer }\end{array}$} & & & & \\
\hline & $2 \min 38 s$ & $5 \min 13 \mathrm{~s}$ & $7 \min 21 \mathrm{~s}$ & $11 \mathrm{~min} 43 \mathrm{~s}$ \\
\hline \multirow{2}{*}{$\begin{array}{l}\text { Emulsion } \\
\text { produced } \\
\text { by motor } \\
\text { and static } \\
\text { mixer }\end{array}$} & & & & \\
\hline & $52 \mathrm{~s}$ & $2 \min 48 s$ & $3 \min 57 s$ & $5 \mathrm{~min} 17 \mathrm{~s}$ \\
\hline
\end{tabular}

Fig. 5. Stability of emulsion produced

\subsection{Fuel Consumption}

Figure 6 showed the fuel consumption for B10 fuel, B10 with electrical load, EMS and EMUS emulsion. When the electrical load was attached to the system, the fuel consumption of B10 fuel with electrical load increased slightly by $1.0 \%$ compared to B10 fuel. This is because the electrical load from the RTES system gives additional loading to the engine which causes the engine to consume 
more fuel to support the system [23]. Plus, the RTES system is connected in parallel connection to battery lorry and alternator.

Generally, when the engine is not running, the energy from the vehicle system is obtained from the battery. After the engine has started, the alternator will take place to supply the current to the devices and charge the battery inside the vehicle. The alternator supplied the electrical energy to the RTES system caused the torque of the engine to increase which causes higher additional work to the engine [24]. Thus, the fuel consumption increased because of the additional load to the engine due to the demand to power up the RTES system from the alternator (ancillary load connected by a pulley attached to the engine).

Meanwhile, comparing the B10 and emulsion fuel, both emulsion fuels showed lower fuel consumption by $1.5 \%$ from EMS and $0.4 \%$ from EMUS. The reduction of fuel consumption was mainly believed to be caused by the micro-explosion phenomenon [20]. The micro explosion further the breakdown of water droplets in EMUS and EMS into smaller droplets to enhance more evaporation in surface area of fuel droplets which resulting better air-fuel mixing in combustion fuel [14-15]. Thus, it is resulting in better fuel consumption compared to B10 fuel. Although the emulsified fuel has lower calorific value and energy content compared to B10, however, the effect of micro explosion more dominant compared to effect of calorific value on fuel consumption [18]. This result in line with observation reported by Khan et al., [11], Ramlan et al., [18], and Shyam et al., [25].

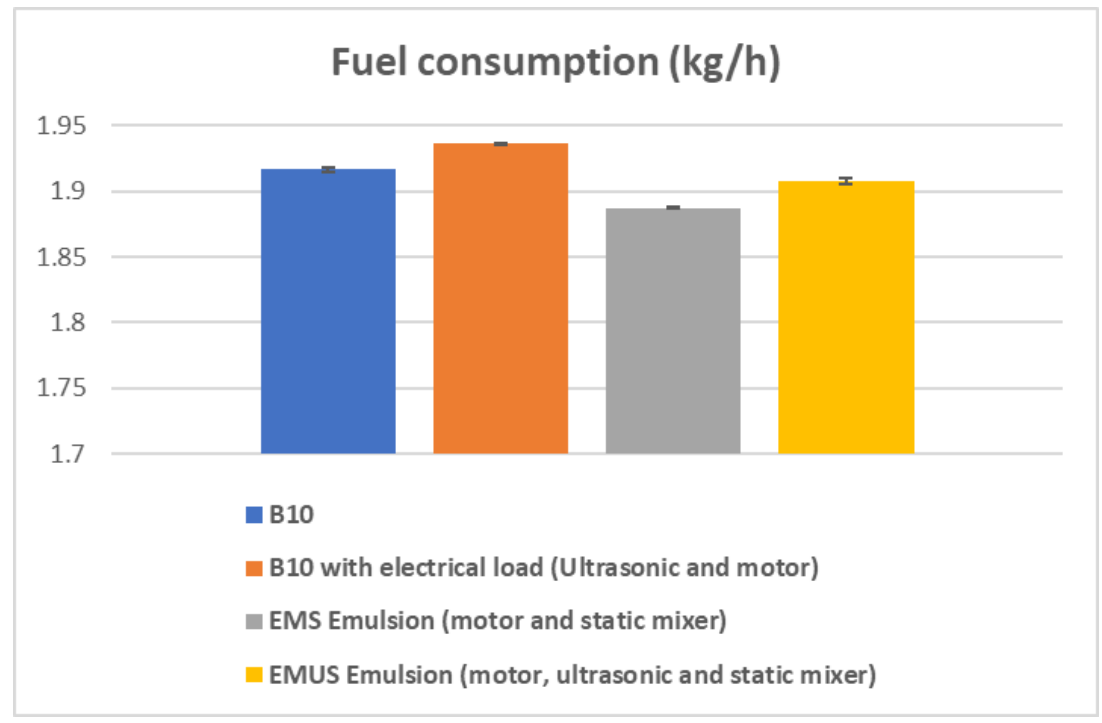

Fig. 6. Fuel consumption

\subsection{Emission Characteristics}

\subsection{1 $\mathrm{NO}_{\mathrm{x}}$ emission}

Figure 7 showed the $\mathrm{NO}_{\mathrm{x}}$ emission. Compared to $\mathrm{B} 10$ fuel, the $\mathrm{NO}_{\mathrm{x}}$ emission was reduced by $7.4 \%$ from emulsion fuel. Meanwhile, the $\mathrm{NO}_{\mathrm{x}}$ emission for both emulsions was almost similar because of the same water content. However, compared to the $\mathrm{B} 10$ fuel, the emulsion had lower $\mathrm{NO}_{\mathrm{x}}$ concentration because of the presence of water. The presence of water in fuel causes the peak temperature in the combustion chamber lower and contributes to the reduction of thermal $\mathrm{NO}_{x}$ during combustion $[6,26]$. This result similar to studies reported by Badran et al., [27], Syu et al., [28] and Maji et al., [29]. 


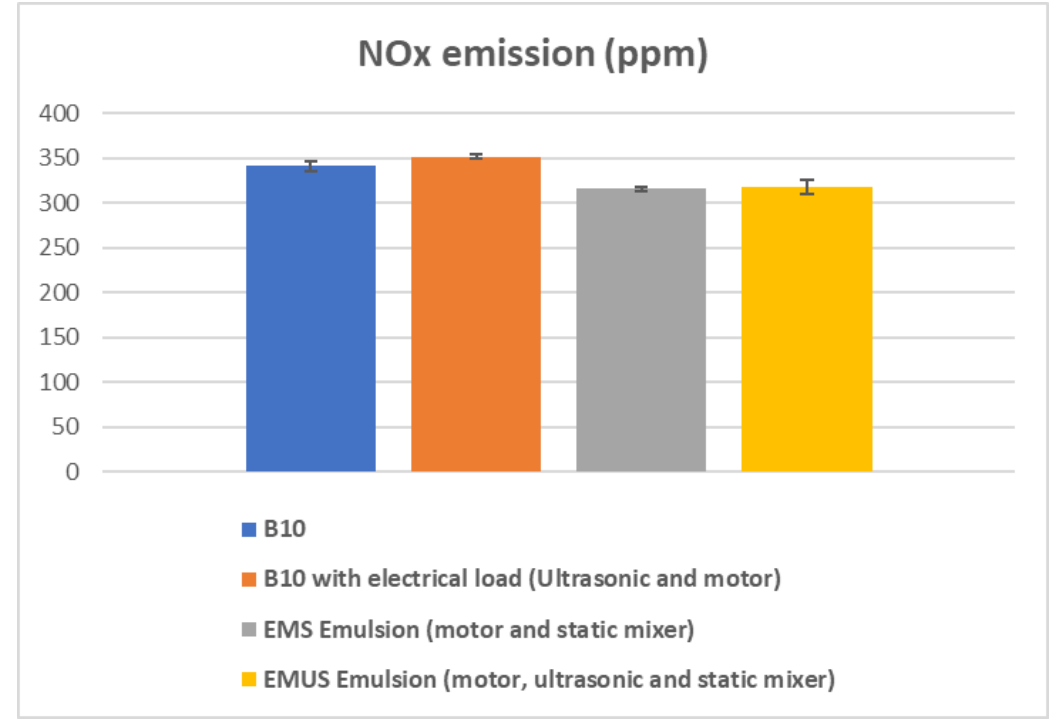

Fig. 7. $\mathrm{NO}_{\mathrm{x}}$ emission

\subsubsection{CO emission}

Figure 8 revealed the $\mathrm{CO}$ emission under the engine condition of 2200rpm for 5 minutes. The emulsion fuel recorded an increase in the CO emission by $20.5 \%$ from EMS and $16.5 \%$ from EMUS, compared to the $\mathrm{B} 10$ fuel. The formation of $\mathrm{CO}$ and $\mathrm{CO} 2$ is interconnected because if $\mathrm{CO} 2$ is increased, the $\mathrm{CO}$ formation will naturally decrease. The main reason the $\mathrm{CO}$ emission increases for emulsified fuel was due to water, which reduced the temperature inside the combustion chamber, limiting the formation of $\mathrm{CO}$. Therefore, decreasing $\mathrm{CO} 2$ emission. Furthermore, the temperature in the combustion chamber needs to be above $1400 \mathrm{~K}$ to initiate the conversion of $\mathrm{CO}$ to $\mathrm{CO} 2$ species [10]. If the temperature below that $1400 \mathrm{~K}$, the oxidation of $\mathrm{CO}$ to $\mathrm{CO} 2$ will freeze[9]. The $\mathrm{OH}$ radicals from the water cause EMS and EMUS high in $\mathrm{CO}$ emission because $\mathrm{OH}$ radicals promoting oxidation carbon to $\mathrm{CO}[13,30]$. This result parallel with the observation reported by Mondal and Mandal [12] and Maji et al., [29].

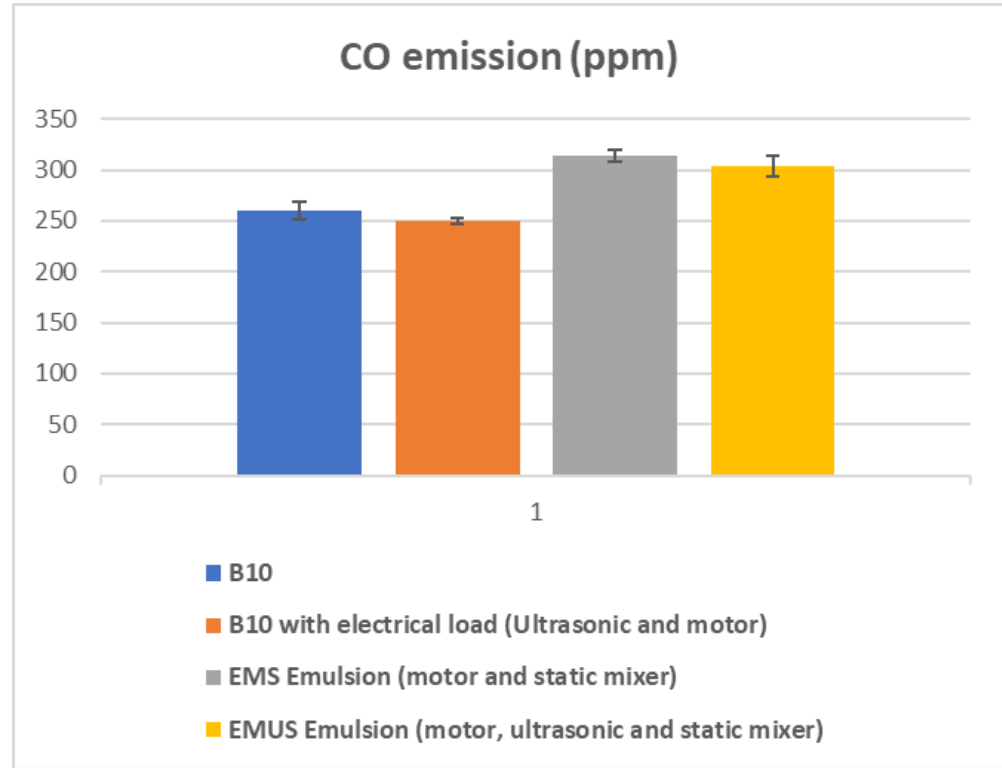

Fig. 8. CO emission 


\subsubsection{Hydrocarbon emission}

The formation of hydrocarbon depends on the ignition delay, micro-explosion, and relative impact of the combustion chamber. Figure 9 showed the formation of unburnt hydrocarbon of diesel fuel, and emulsion from 2 different conditions. Its crystal clear that the emulsion fuel produced more HC emission compared to diesel by $16.9 \%$ for EMS and $9.7 \%$ for EMUS, respectively. This is attributed to incomplete combustion of emulsified fuel EMS and EMUS compared to B10. The water particles inside the EMS and EMUS fuel are in closed contact with diesel fuel thus resulting the combustion process inside the combustion chamber is quenched [12]. This situation thwarted the atomization of the fuel and increased the $\mathrm{HC}$ emission. Furthermore, the EMS had higher production of $\mathrm{HC}$ emission compared to EMUS. This could be the formation of EMS emulsion was quite unstable compare to EMUS emulsion. Meanwhile, the presence of ultrasonic in EMUS emulsion could be reason the emulsion produced more stable compared to EMS because emulsion from EMUS more uniform in term water particle distribution compared to EMS which resulting difference HC formation when comparing both emulsion.

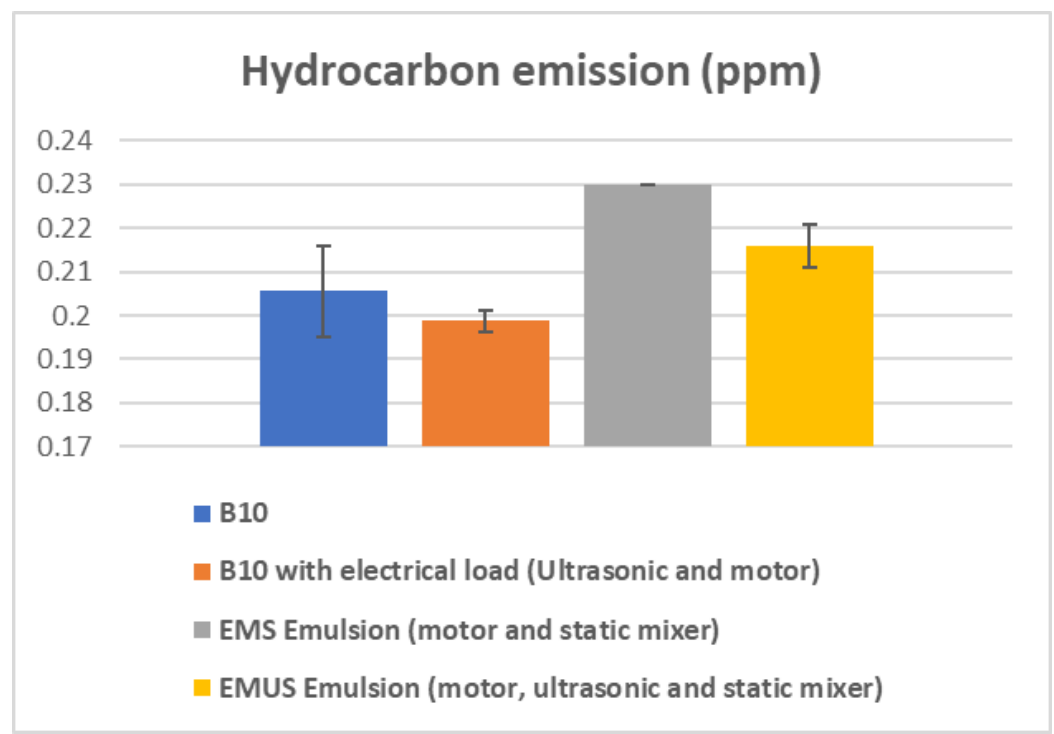

Fig. 9. $\mathrm{HC}$ emission

\section{Conclusion}

Based on this experimental investigation, the conclusions that can be drawn in this research are

i. The fuel consumption for B10 with electrical load increased slightly compared to the B10 fuel but reduced slightly when compared to emulsion fuel.

ii. NOx emission by both Emulsion fuels showed a significant reduction of approximately $7 \%$ compared to B10 diesel fuel on NOx emission.

iii. CO emission for emulsified fuel increased drastically by $20 \%$ for EMS and $16 \%$ for EMUS respectively, when compared to B10 diesel fuel.

iv. The Hydrocarbon emission increased by $16.9 \%$ for EMS emulsion and $9.7 \%$ for EMUS compared to the B10 diesel fuel.

Overall, this study had shown that any additional electrical load does increase fuel consumption by $1.0 \%$. Furthermore, the introduction of the static mixer in RTES showed a promising result in emulsification which showed better fuel consumption and exhaust emission reduction even without the presence of ultrasonic transducer during the mixing period. 


\section{Acknowledgment}

The authors would like to express their gratitude to the Malaysia-Japan International Institute of Technology (MJIIT) for providing the research with the needed facilities and equipment. Highest appreciation goes to Universiti Teknologi Malaysia for the financial support through research grant (Q.K130000.3543.05G13).

\section{References}

[1] Vellaiyan, Suresh, and K. S. Amirthagadeswaran. "The role of water-in-diesel emulsion and its additives on diesel engine performance and emission levels: A retrospective review." Alexandria Engineering Journal 55, no. 3 (2016): 2463-2472.https://doi.org/10.1016/j.aej.2016.07.021

[2] Mondal, Pijush Kanti, and Bijan Kumar Mondal. "Combustion and performance characteristics of a diesel engine using emulsified diesel prepared by ultrasonicator." In 2017 International Conference on Advances in Mechanical, Industrial, Automation and Management Systems (AMIAMS), pp. 172-178. IEEE, 2017. https://doi.org/10.1109/AMIAMS.2017.8069207

[3] Hasannuddin, A. K., J. Y. Wira, R. Srithar, S. Sarah, M. I. Ahmad, S. A. Aizam, M. A. B. Aiman et al. "Effect of emulsion fuel on engine emissions-A review." Clean Technologies and Environmental Policy 18, no. 1 (2016): 17-32. https://doi.org/10.1007/s10098-015-0986-x

[4] European Union. "Worldwide Emission Standards and Related Regulations - Passenger Cars / Light and Medium Duty Vehicles.".Cont. Futur. Motion, no. May (2019).

[5] Ithnin, Ahmad Muhsin, Hirofumi Noge, Hasannuddin Abdul Kadir, and Wira Jazair. "An overview of utilizing waterin-diesel emulsion fuel in diesel engine and its potential research study." Journal of the Energy Institute 87, no. 4 (2014): 273-288. https://doi.org/10.1016/i.joei.2014.04.002

[6] Jhalani, Amit, Dilip Sharma, Shyam Lal Soni, Pushpendra Kumar Sharma, and Sumit Sharma. "A comprehensive review on water-emulsified diesel fuel: chemistry, engine performance and exhaust emissions." Environmental Science and Pollution Research 26, no. 5 (2019): 4570-4587. https://doi.org/10.1007/s11356-018-3958-y

[7] Imazu, Hiroki, and Yoshihiro Kojima. "Physical properties and combustion characteristics of emulsion fuels of water/diesel fuel and water/diesel fuel/vegetable oil prepared by ultrasonication." Journal of the Japan Petroleum Institute 56, no. 1 (2013): 52-57.

https://doi.org/10.1627/ipi.56.52

[8] Ramlan, Nur Atiqah, Wira Jazair Yahya, Ahmad Muhsin Ithnin, A. K. Hasannuddin, Siti Amiliyana Norazni, Nurul Aiyshah Mazlan, Dhani Avianto Sugeng, Nadia Dayana Bahar, and Tsuyoshi Koga. "Performance and emissions of light-duty diesel vehicle fuelled with non-surfactant low grade diesel emulsion compared with a high grade diesel in Malaysia." Energy Conversion and Management 130 (2016): 192-199.

https://doi.org/10.1016/i.enconman.2016.10.057

[9] Mazlan, Nurul Aiyshah, Wira Jazair Yahya, Ahmad Muhsin Ithnin, and Mohamad Azrin Ahmad. "The effect of tap water emulsified fuel on exhaust emission of single cylinder compression ignition engine." In MATEC Web of Conferences, vol. 90, p. 01054. EDP Sciences, 2017. https://doi.org/10.1051/matecconf/20179001054

[10] Mondal, Pijush Kanti, and Bijan Kumar Mandal. "A comprehensive review on the feasibility of using water emulsified diesel as a Cl engine fuel." Fuel 237 (2019): 937-960. https://doi.org/10.1016/i.fuel.2018.10.076

[11] Yahaya Khan, Mohammed, Z. A. Abdul Karim, Ftwi Yohaness Hagos, A. Rashid A. Aziz, and Isa M. Tan. "Current trends in water-in-diesel emulsion as a fuel." The Scientific World Journal 2014 (2014). https://doi.org/10.1155/2014/527472

[12] Mondal, Pijush Kanti, and Bijan Kumar Mandal. "Optimization of water-emulsified diesel preparation and comparison of mechanical homogenization and ultrasonic dispersion methods to study $\mathrm{Cl}$ engine performances." Energy Sources, Part A: Recovery, Utilization, and Environmental Effects (2019): 1-30. https://doi.org/10.1080/15567036.2019.1675811

[13] Lif, Anna, and Krister Holmberg. "Water-in-diesel emulsions and related systems." Advances in colloid and interface science 123 (2006): 231-239. https://doi.org/10.1016/j.cis.2006.05.004

[14] Abd Razak, Ili Fatimah, Wira Jazair Yahya, Ahmad Muhsin Ithnin, Muhammad Afiq Haikal, Muhammad Ahmar Zuber Norazman, and Nur Atiqah Ramlan. "Burner Performance and Emissions Fuelled with Water-in-Diesel Emulsion Fuel." Journal of Advanced Research in Fluid Mechanics and Thermal Sciences 65, no. 1 (2020): 13-24.

[15] Ithnin, Ahmad Muhsin, Wira Jazair Yahya, Mohamad Azrin Ahmad, Nur Atiqah Ramlan, Hassanuddin Abdul Kadir, Nor Azwadi Che Sidik, and Tsuyoshi Koga. "Emulsifier-free Water-in-Diesel emulsion fuel: Its stability behaviour, engine performance and exhaust emission." Fuel 215 (2018): 454-462. https://doi.org/10.1016/i.fuel.2017.11.061 
[16] Mazlan, Nurul Aiyshah, Wira Jazair Yahya, Ahmad Muhsin Ithnin, A. K. Hasannuddin, Nur Atiqah Ramlan, Dhani Avianto Sugeng, AR Muhammad Adib, Tsuyoshi Koga, Rizalman Mamat, and Nor Azwadi Che Sidik. "Effects of different water percentages in non-surfactant emulsion fuel on performance and exhaust emissions of a light-duty truck." Journal of cleaner production 179 (2018): 559-566. https://doi.org/10.1016/j.jclepro.2018.01.143

[17] Yahya, W. J., A. M. Ithnin, H. A. Kadir, N. A. Mazlan, and S. A. Norazni. "Performance of Diesel Engine Equipped with Real-Time Non-Surfactant Emulsion Fuel Supply System (RTES)." Journal of Advanced Vehicle System 1, no. 1 (2016): 1-7.

[18] Ramlan, Nur Atiqah, Wira Jazair Yahya, Ahmad Muhsin Ithnin, Hasannuddin Abd Kadir, Khairil Anwar Abu Kassim, Hasbullah Abdul Rahman, Arif Fahim Ezzat Chan, Nurul Aisyah Mazlan, Muhammad Adib Abdul Rashid, and Dhani Avianto Sugeng. "Emissions and performance analysis of diesel powered road vehicle equipped with real-time nonsurfactant emulsion fuel supply system." Fuel 273 (2020): 117257. https://doi.org/10.1016/i.fuel.2020.117257

[19] C. Ross. "Static Mixer Designs and Applications." (2015): 1-10.

[20] Rashid, Muhammad Adib Abdul, Ahmad Muhsin Ithnin, Wira Jazair Yahya, Nur Atiqah Ramlan, Nurul Aiyshah Mazlan, and Dhani Avianto Sugeng. "Integration of real-time non-surfactant emulsion fuel system on light duty lorry." In IOP Conference Series: Materials Science and Engineering; IOP: London, UK, vol. 257, p. 012051.2017. https://doi.org/10.1088/1757-899X/257/1/012051

[21] "Petron diesel max." (2014): 70916.

[22] Ecom. "J2KN PRO Series." https://envcoglobal.com/files/docs/j2kn-pro2012-spec-sheet-2012.pdf

[23] Carlson, Richard'barney, Matthew G. Shirk, and Benjamin M. Geller. "Factors affecting the fuel consumption of plug-in hybrid electric vehicles." In 25th World Batter. Hybrid Fuel Cell Electr. Veh. Symp. Exhib., pp. 289--294, 2010.

[24] Lee, Jungwoo, Jaeheun Kim, Jungseo Park, and Choongsik Bae. "Effect of the air-conditioning system on the fuel economy in a gasoline engine vehicle." Proceedings of the Institution of Mechanical Engineers, Part D: Journal of Automobile Engineering 227, no. 1 (2013): 66-77.

https://doi.org/10.1177/0954407012455973

[25] Prasad, H. Shyam, Joseph Gonsalvis, and V. S. Vijay. "Effect of introduction of water into combustion chamber of diesel engines-a review." Energy and Power 5, no. 1A (2015): 28-33.

[26] Kojima, Yoshihiro, Hiroki Imazu, and Keiichi Nishida. "Physical and chemical characteristics of ultrasonicallyprepared water-in-diesel fuel: effects of ultrasonic horn position and water content." Ultrasonics sonochemistry 21, no. 2 (2014): 722-728. https://doi.org/10.1016/j.ultsonch.2013.09.019

[27] Badran, Omar, Sadeq Emeishb, Mahmoud Abu-Zaidc, Tayseer Abu-Rahmaa, Mohammad Al-Hasana, and Mumin AlRagheba. "Impact of emulsified water/diesel mixture on engine performance and environment." Int. J. of Thermal \& Environmental Engineering 3, no. 1 (2011): 1-7. https://doi.org/10.5383/ijtee.03.01.001

[28] Syu, Jin-Yuan, Yuan-Yi Chang, Chao-Heng Tseng, Yeou-Lih Yan, Yu-Min Chang, Chih-Chieh Chen, and Wen-Yinn Lin. "Effects of water-emulsified fuel on a diesel engine generator's thermal efficiency and exhaust." Journal of the Air \& Waste Management Association 64, no. 8 (2014): 970-978. https://doi.org/10.1080/10962247.2014.905508

[29] Maji, Debdut, P. Mondal, and B. Kumar Mandal. "Experimental investigation on the use of water emulsified diesel in a single cylinder Compression Ignition engine." In International Conference on Mechanical, Material and Renewable Energy. IOP Conf. Series: Material Science and Engineering, vol. 377, p. 012123.2018. https://doi.org/10.1088/1757-899X/377/1/012123

[30] Koc, A. Bulent, and Mudhafar Abdullah. "Performance and NOx emissions of a diesel engine fueled with biodieseldiesel-water nanoemulsions." Fuel Processing $\quad$ Technology $109 \quad$ (2013): https://doi.org/10.1016/i.fuproc.2012.09.039 